\title{
Differential Expression Profiles of the Transcriptome and miRNA Interactome in Synovial Fibroblasts of Rheumatoid Arthritis Revealed by Next Generation Sequencing
}

\author{
Chia-Chun Tseng ${ }^{1,2}$, Ling-Yu Wu ${ }^{1}$, Wen-Chan Tsai ${ }^{3}$, Tsan-Teng $\mathrm{Ou}^{3}$, Cheng-Chin $\mathrm{Wu}^{3}$, \\ Wan-Yu Sung ${ }^{3}$, Po-Lin Kuo ${ }^{1,4, * \mathbb{D}}$ and Jeng-Hsien Yen ${ }^{1,3,4, *}$ \\ 1 Graduate Institute of Clinical Medicine, College of Medicine, Kaohsiung Medical University, \\ Kaohsiung 80708, Taiwan \\ 2 Department of Internal Medicine, Kaohsiung Municipal Ta-Tung Hospital, Kaohsiung 80145, Taiwan \\ 3 Division of Rheumatology, Department of Internal Medicine, Kaohsiung Medical University Hospital, \\ Kaohsiung 80708, Taiwan \\ 4 Institute of Biomedical Science, National Sun Yat-Sen University, Kaohsiung 80424, Taiwan \\ * Correspondence: kuopolin@seed.net.tw (P.-L.K.); jehsye@cc.kmu.edu.tw (J.-H.Y.); \\ Tel.: +886-7-312-1101-2512 (P.-L.K.); +886-7-3121101-6088 (J.-H.Y.); Fax: +886-7-3118141 (J.-H.Y.)
}

Received: 12 July 2019; Accepted: 13 August 2019; Published: 18 August 2019

\begin{abstract}
Using next-generation sequencing to decipher the molecular mechanisms underlying aberrant rheumatoid arthritis synovial fibroblasts (RASF) activation, we performed transcriptome-wide RNA-seq and small RNA-seq on synovial fibroblasts from rheumatoid arthritis (RA) subject and normal donor. Differential expression of mRNA and miRNA was integrated with interaction analysis, functional annotation, regulatory network mapping and experimentally verified miRNA-target interaction data, further validated with microarray expression profiles. In this study, 3049 upregulated mRNA and 3552 downregulated mRNA, together with 50 upregulated miRNA and 35 downregulated miRNA in RASF were identified. Interaction analysis highlighted contribution of miRNA to altered transcriptome. Functional annotation revealed metabolic deregulation and oncogenic signatures of RASF. Regulatory network mapping identified downregulated FOXO1 as master transcription factor resulting in altered transcriptome of RASF. Differential expression in three miRNA and corresponding targets (hsa-miR-31-5p:WASF3, hsa-miR-132-3p:RB1, hsa-miR-29c-3p:COL1A1) were also validated. The interactions of these three miRNA-target genes were experimentally validated with past literature. Our transcriptomic and miRNA interactomic investigation identified gene signatures associated with RASF and revealed the involvement of transcription factors and miRNA in an altered transcriptome. These findings help facilitate our understanding of RA with the hope of serving as a springboard for further discoveries relating to the disease.
\end{abstract}

Keywords: rheumatoid arthritis; miRNA; synovial fibroblast

\section{Introduction}

Rheumatoid arthritis (RA) is an autoimmune disease characterized by sustained chronic inflammation resulting in joint damage and severe disability. New and more effective therapies developed over the past two decades targeting the inflammatory mediators and immune cells $[1,2]$ have revolutionized the management of RA [3]. However, disease remission remains uncommon [4]. Furthermore, therapies targeting different aspects of the immune response render patients more 
susceptible to infection [5]. In light of these challenges, approaches that focus on other components of joint inflammation have been proposed as potential solutions [4].

In RA, inflammatory cytokines, such as interleukin (IL)-6 and tumor necrosis factor-alpha (TNF- $\alpha$ ), cause dysregulated proliferation and drive a migratory and invasive phenotype of synovial fibroblast [6,7] (also known as fibroblast-like synoviocytes (FLS)) [8], resulting in pannus formation. Synovial fibroblasts are directly involved in cartilage and bone destruction by production of matrix metalloproteinases (MMPs) and activation of osteoclasts through receptor activator of nuclear factor kappa-B ligand (RANKL) [8]. Synovial fibroblasts also contribute to inflammatory amplification via IL-6 production [9]. Although immune cells and inflammatory mediators have been feasible targets for RA treatment $[1,2,10]$, there has never been a treatment strategy targeting specifically the aggressiveness of synovial fibroblasts. Compared with inflammatory mediators and immune cells, little is known about the causes of the particularly aggressive nature of RA synovial fibroblasts. Therefore, a more comprehensive understanding of synovial fibroblasts in RA may yield promising novel therapeutic targets.

A substantial number of epigenetic mechanisms are known to regulate dynamic changes in gene expression of various cells. MicroRNA (miRNA) is one best-known mechanism which plays a central role in post-transcriptional modification of gene expression via antisense binding to messenger RNA (mRNA). It was well-established that miRNA participated in pathophysiological processes of various autoimmune diseases, such as ankylosing spondylitis and uveitis $[11,12]$. However, the roles of miRNA in RA synovial fibroblasts were less clear.

In the past, several studies explored transcriptome of RA synovial fibroblasts utilizing RNA-seq [13,14]. However, they compared transcriptome changes before and after inflammatory mediator stimulation rather than transcriptome differences between RA and normal donors. Moreover, whether and how miRNA contributed to transcriptome changes in RA was not fully understood. To explore the full mRNA transcriptome and miRNA interactome of RA synovial fibroblasts in genome-wide scale, we performed transcriptome-wide RNA-seq and small RNA-seq in synovial fibroblasts from RA patient and normal donor to reveal changes to the synovial fibroblasts transcriptome and to elucidate the contributing miRNA to transcription signatures in RA synovial fibroblasts. We further applied interaction analysis of transcription factors, miRNA, and target genes, functional annotation and regulatory network mapping to elucidate involved molecular programs. Experimentally validated targets of miRNA and data from publicly available databases were integrated to validate our results. These results offer a map to the synovial fibroblasts transcriptome and miRNA interactome and shed light on the pathophysiology of RA.

\section{Methods}

\subsection{Synovial Fibroblasts}

Primary human synovial fibroblasts isolated from one normal donor and one RA subject were obtained from Cell Applications Inc (San Diego, CA, USA). Synovial fibroblasts were cultured with Synoviocyte Growth Medium (Cell Applications Inc. San Diego, CA, USA) at $37^{\circ} \mathrm{C}$ and $5 \% \mathrm{CO}_{2}$. When the cells had grown to confluence, the normal synovial fibroblasts and RA synovial fibroblasts were harvested for total RNA extraction and transcriptome profiling. First passage synovial fibroblasts were used for this study to avoid the influence of repeated passages and accumulation of chromosomal aberrations, which may influence gene expression. The study was exempted from the institutional review board requirement because the research utilized de-identified human cells obtained from commercial entities.

\subsection{RNA Extraction}

RNA was isolated from primary cultured synovial fibroblasts with the Trizol reagent (Invitrogen, Carlsbad, CA, USA) for generation of both long and small RNA libraries for sequencing. The RNA 
quantity and quality were evaluated using the ND-1000 spectrophotometer (Nanodrop Technology, Wilmington, DE, USA) and the Agilent RNA 6000 labchip kit with Agilent 2100 Bioanalyzer instrument (Agilent Technologies Inc, Santa Clara, CA, USA), respectively. The qualities of extracted RNA were shown in Table S1.

\subsection{RNA-Seq}

Agilent's SureSelect Strand Specific RNA Library Preparation Kit was used for library construction. Briefly, RNA was purified and fragmented using poly-T oligo-attached magnetic beads followed by complementary DNA (cDNA) strand synthesis. Next, cDNA 3' ends were adenylated and adapters ligated followed by library amplification. The libraries were size-selected using AMPure XP Beads (Beckman Coulter). The sequence was directly determined using sequencing-by-synthesis technology on Illumina/Solexa platform (150 paired-end cycles) via the TruSeq SBS Kit. Raw sequences were obtained from the Illumina Pipeline software bcl2fastq v2.0 to generate total reads of $9 \mathrm{G}$ per sample. For RNA-seq analysis, initially the sequences generated went through a filtering process to obtain qualified reads. Trimmomatic was implemented to trim or remove the reads according to the quality score. HISAT2 was used for mapping and alignment to reference human genomes, based on hierarchical graph FM index (GFM index) [15]. The gene expression level was calculated as Fragments Per Kilobase of transcript per Million mapped reads (FPKM). Further differential expression analysis was performed based on cuffdiff (cufflinks version 2.2.1) with genome bias detection/correction [16].

\subsection{Small RNA-Seq}

The Illumina TruSeq Small RNA sample preparation protocol was used to produce the small RNA-seq libraries from total RNA. Briefly, total RNA were ligated with $3^{\prime}$ and $5^{\prime}$ adaptors and reverse transcribed followed by polymerase chain reaction (PCR) amplification to obtain cDNA constructs. The enriched cDNA constructs were size-fractionated and purified on a $6 \%$ polyacrylamide gel electrophoresis with the bands containing the 18-40 nucleotide RNA fragments (140-155 nucleotides in length with both adapters). Then, $75 \mathrm{bp}$ single-end sequencing was performed on Illumina/Solexa platform with total reads of $10 \mathrm{M}$ per sample. Sequencing data was processed with the Illumina software. We used miRDeep2 to analyze the generated raw data, evaluate the overall sequencing qualities and determine the miRNA expression profiles. For expression analysis of miRNA, the gene expression level was calculated as Reads Per Million (RPM).

\subsection{RNA-Seq Analysis}

To identify differentially expressed mRNA from RNA-seq data, we adopted previous protocols [17]. Briefly, we retrieved mRNA with a minimum absolute fold change of 2 [17] and FPKM $>0.3$ in RA or normal donor (Figure 1), since a threshold FPKM value of 0.3 balanced the numbers of false positives and false negatives [18].

\subsection{Small RNA-Seq Analysis}

In small RNA-seq analysis, we set the criteria of differential expression based on past studies $[19,20]$. To identify differentially expressed miRNA, we retrieved miRNA with a minimum absolute fold change of 1.5 [19] and RPM > 10 in RA or normal donor, since a threshold of 10 RPM identified all functional miRNAs while removing many inconsequential reads [20] (Figure 1). 


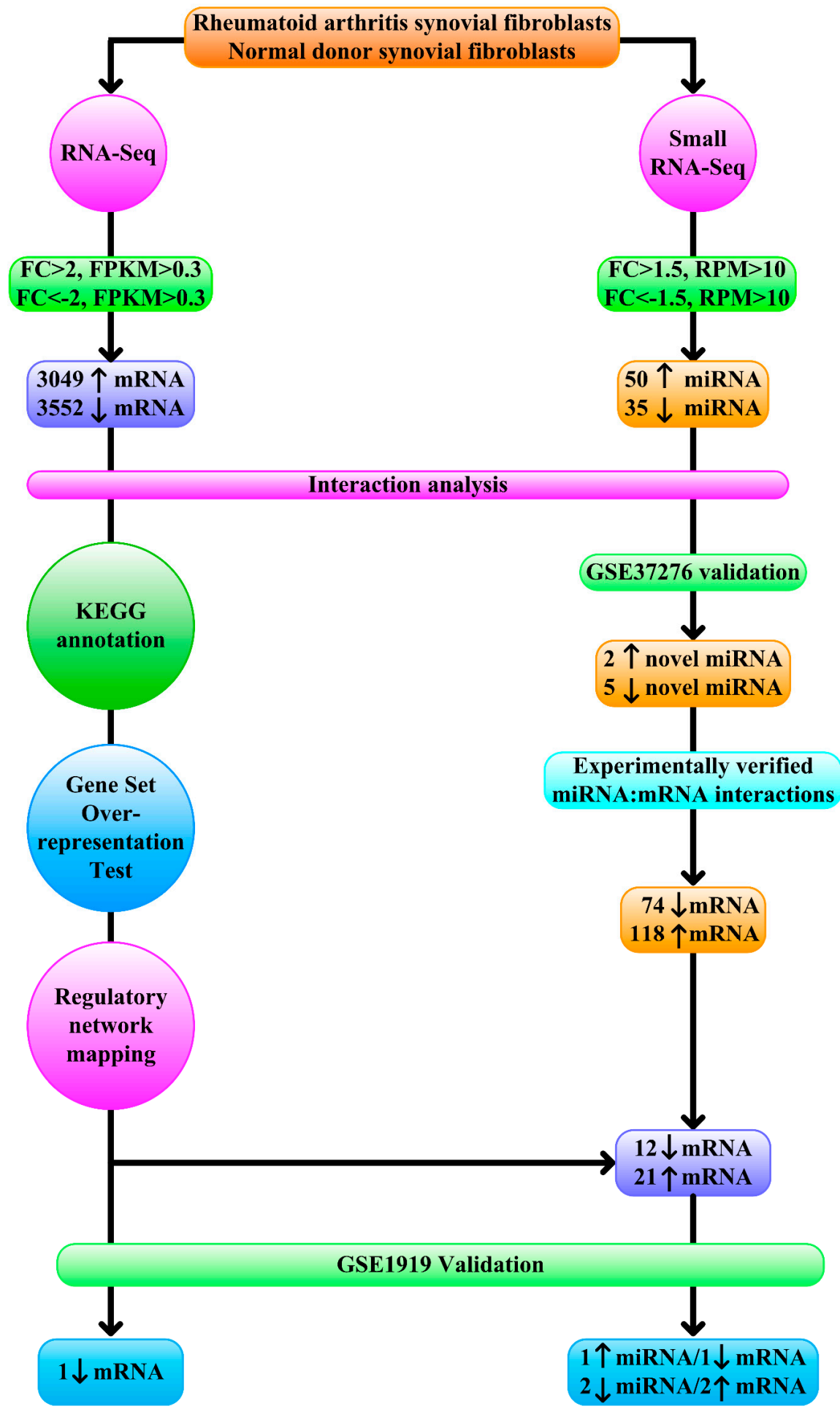

Figure 1. Schematic representation of the next-generation sequencing data analytical workflow. 3049 upregulated (fold change $>2$, Fragments Per Kilobase of transcript per Million (FPKM) > 0.3), 3552 downregulated protein-coding mRNA (fold change $<-2$, FPKM $>0.3$ ), 50 upregulated (fold change $>$ 1.5 , Reads Per Million $(\mathrm{RPM})>10$ ), and 35 downregulated (fold change $<-1.5, \mathrm{RPM}>10$ ) miRNA were examined with interaction analysis. Kyoto Encyclopedia of Genes and Genomes (KEGG) annotation, Gene Set Overrepresentation Test, regulatory network mapping, and mRNA validation with GSE1919 identified one downregulated mRNA as master regulator. Seven novel miRNAs were also verified with GSE37276. Of 74 downregulated and 118 upregulated mRNA as experimentally verified targets of validated novel miRNA, 12 and 21 displayed concordant changes in RNA-seq, and one downregulated and two upregulated mRNA were validated with GSE1919. 


\subsection{Interaction Analysis of Transcription Factors, miRNA, and Target Genes}

Taking advantage of TFmiR [21], differentially expressed protein-coding mRNA and miRNA and interactions between them were tested for overrepresentation of RA-specific networks and significance of transcription factor-target gene interaction and miRNA-target gene interaction (Figure 1). TFmiR utilized information provided by established regulatory databases of experimentally validated interactions and scientific literature to facilitate research on transcriptional and post-transcriptional interactions between transcription factors, miRNA and target genes. The significance of transcriptional and post-transcriptional regulatory interactions from deregulated mRNA and miRNA was assessed using the hypergeometric distribution test. It also assessed relevance of the provided deregulated inputs to the disease-associated genes/miRNA.

\subsection{Transcript Functional Annotation}

To better appreciate the functional picture of differentially expressed mRNA, we employed Kyoto Encyclopedia of Genes and Genomes (KEGG) database [22] to generate functional maps of differentially expressed mRNA (Figure 1). Gene Set Overrepresentation Test was executed with PANTHER [23] to yield insights into biological pathways involved in RA (Figure 1).

\subsection{Regulatory Network Mapping}

For discovery of enriched transcription factors and their targets in the RNA-seq data, we executed iRegulon [24] that utilized ChIP-Seq and motif occurrence information to elucidate master transcription factors driving differentially expressed genes observed in RA synovial fibroblasts (Figure 1). The identified master transcription factors were validated with the Gene Expression Omnibus (GEO) dataset GSE1919 [25] to confirm differential expression of identified master transcription factor (Figure 1). The Gene Multiple Association Network Integration Algorithm (GeneMANIA) was queried to investigate the most related genes to reconstruct regulatory networks from validated master transcription factors [26].

\subsection{0. miRNA Profile Validation}

To confirm differential expression of miRNA between RA synovial fibroblasts and normal fibroblasts, we retrieved expression profiles of miRNA in RA synovial fibroblasts and normal fibroblasts from GSE37276 [27] (Figure 1). Validated differentially expressed miRNAs were reserved for further investigation.

\subsection{Experimentally Validated Targets of Validated Differentially Expressed miRNA}

To identify experimentally validated targets of differentially expressed miRNA, we downloaded targets of differentially expressed miRNA with strong experimental evidence (reporter assay or Western blot) from miRTarBase [28] (Figure 1). Overlap of differentially expressed mRNA in RNA-seq data and experimentally validated targets of validated differentially expressed miRNA were compared with the GEO dataset GSE1919 [25] to confirm differential expression of targets of validated differentially expressed miRNA (Figure 1).

\subsection{Statistical Analysis}

For the Gene Set Overrepresentation Test, pathways with a false discovery rate less than 0.05 were considered significantly enriched. During validation with GEO dataset, expression profiles obtained from GEO dataset [25,27] were analyzed with GEO2R [29]. We intersected genes with differential expression in RNA-seq/small RNA-seq with probes of GEO dataset. P values less than 0.05 in GEO dataset were considered validation in GEO dataset. 


\section{Results}

\subsection{Contribution of Transcription Factors and miRNA to Differentially Expressed mRNA}

In the RNA-seq analysis (Figure 1), we identified a total of 6601 differentially expressed protein-coding mRNA-3049 upregulated mRNA and 3552 downregulated mRNA (Figure S1, Figure S2A). The details of upregulated mRNA and downregulated mRNA were shown in Tables S2 and S3. In the small RNA-seq analysis (Figure 1), 50 upregulated miRNA and 35 downregulated miRNAs were discovered (Figure S1, Figure S2B). The details of upregulated miRNA and downregulated miRNA are shown in Tables S4 and S5. As expected, significant overlaps of dysregulated miRNA/mRNA with RA-specific network were noted $\left(p=8.48 \times 10^{-17}\right)$ (Figure 2). This observation indicated a contribution of dysregulated miRNA/mRNA to RA development. Additionally, transcription factors and dysregulated miRNA in RA synovial fibroblasts both contributed significantly to altered mRNA expression ( $p=8.30 \times 10^{-7}$ and $p=2.03 \times 10^{-24}$, respectively) (Figure 2).

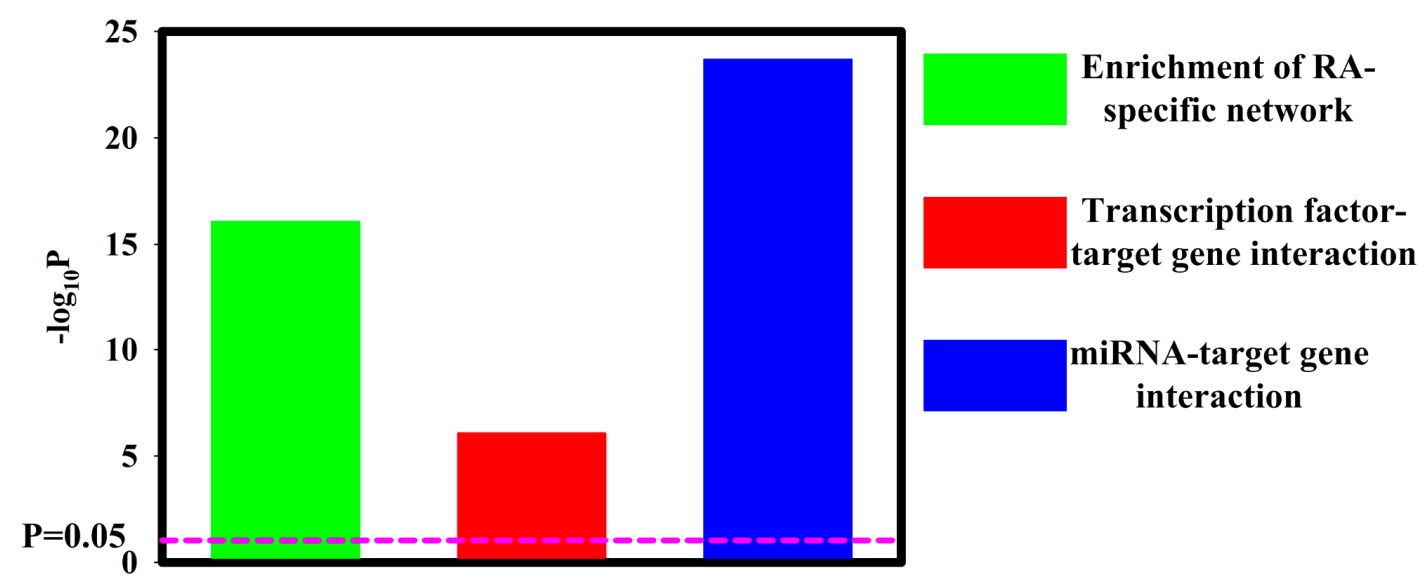

Figure 2. Interaction analysis of transcription factors, miRNA, and target genes. TFmiR analysis revealed significant enrichment of RA-specific network $\left(p=8.48 \times 10^{-17}\right)$. Significant transcription factor-target gene interaction $\left(8.30 \times 10^{-7}\right)$ and miRNA-target gene interaction $\left(2.03 \times 10^{-24}\right)$ were revealed.

\subsection{Functional Annotation Differentially Expressed $m R N A$}

To better understand the molecular functions associated with differentially expressed mRNA, we utilized KEGG database to perform function annotation (Figure 1). Interestingly, the top-ranking category associated with both upregulated and downregulated mRNA was metabolic pathway (Figure S3). Since tumor cells are well documented to rewire their metabolism and energy production networks to support and enable rapid proliferation, continuous growth, survival in harsh conditions, invasion, metastasis and resistance to cancer treatments [30], these metabolic changes might be necessary to cater to demands of sustained inflammation and aggressive natures in RA synovial fibroblasts.

Further analysis with Gene Set Overrepresentation Test for upregulated mRNA (Figure 1) identified several proliferation and migration related pathways enriched in upregulated genes, including cell division, mitotic cell cycle checkpoint, mitotic cell cycle phase, mitotic cell cycle phase transition, regulation of cell cycle activity and regulation of epithelial cell migration (Figure S4). In contrast, these proliferation and migration-related pathways were not associated with downregulated genes (Figure S5) in Gene Set Overrepresentation Test for downregulated mRNA (Figure 1). The data collectively supported previous observations that RA synovial exhibited numerous tumor-like characteristics with excessive proliferation, migration and invasion [31-33].

\subsection{Regulatory Network Mapping}

To gain insight in the spectrum of transcription factors that could drive the altered mRNA transcriptome in RA synovial fibroblasts, we used iRegulon [24] to map the transcription factors 
predicted to act as upstream regulators for upregulated and downregulated mRNA (Figure 1). Nine transcription factors whose expression in RA synovial fibroblasts and normal donor synovial fibroblasts not previously studied were predicted to act as upstream regulators (Figure 3). One transcription factor (FOXO1) showed differential expression in both RNA-seq data (Figure S2A, Figure 3) and GEO dataset GSE1919 [25] (Figure 4A). Gene interaction of FOXO1 with other proteins visualized by GeneMANIA is shown in Figure 4B.

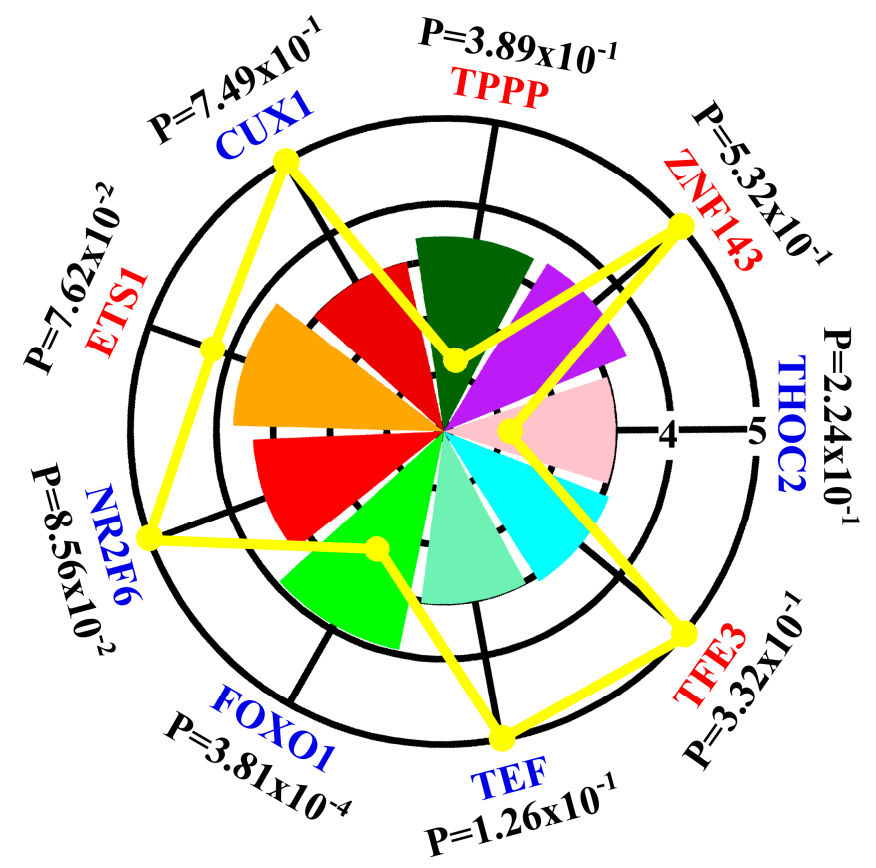

Figure 3. Graphical representation of the iRegulon analysis results. Each chart slice corresponded to a transcription factor identified by iRegulon whose radius was associated normalized enrichment score. The color of the transcription factor indicated upregulation (red) or downregulation (blue) in RNA-seq data and the yellow line showed corresponding absolute values of fold change in RNA-seq data. P values indicated results of validation with GSE1919. For example, FOXO1 is one transcription factor identified by iRegulon which was downregulated (blue color) with fold change -2.38 (yellow line) in RNA-seq and normalized enrichment score 3.92 (green slice). Validation with GSE1919 yielded $P$ value of $3.81 \times 10^{-4}$. 
A
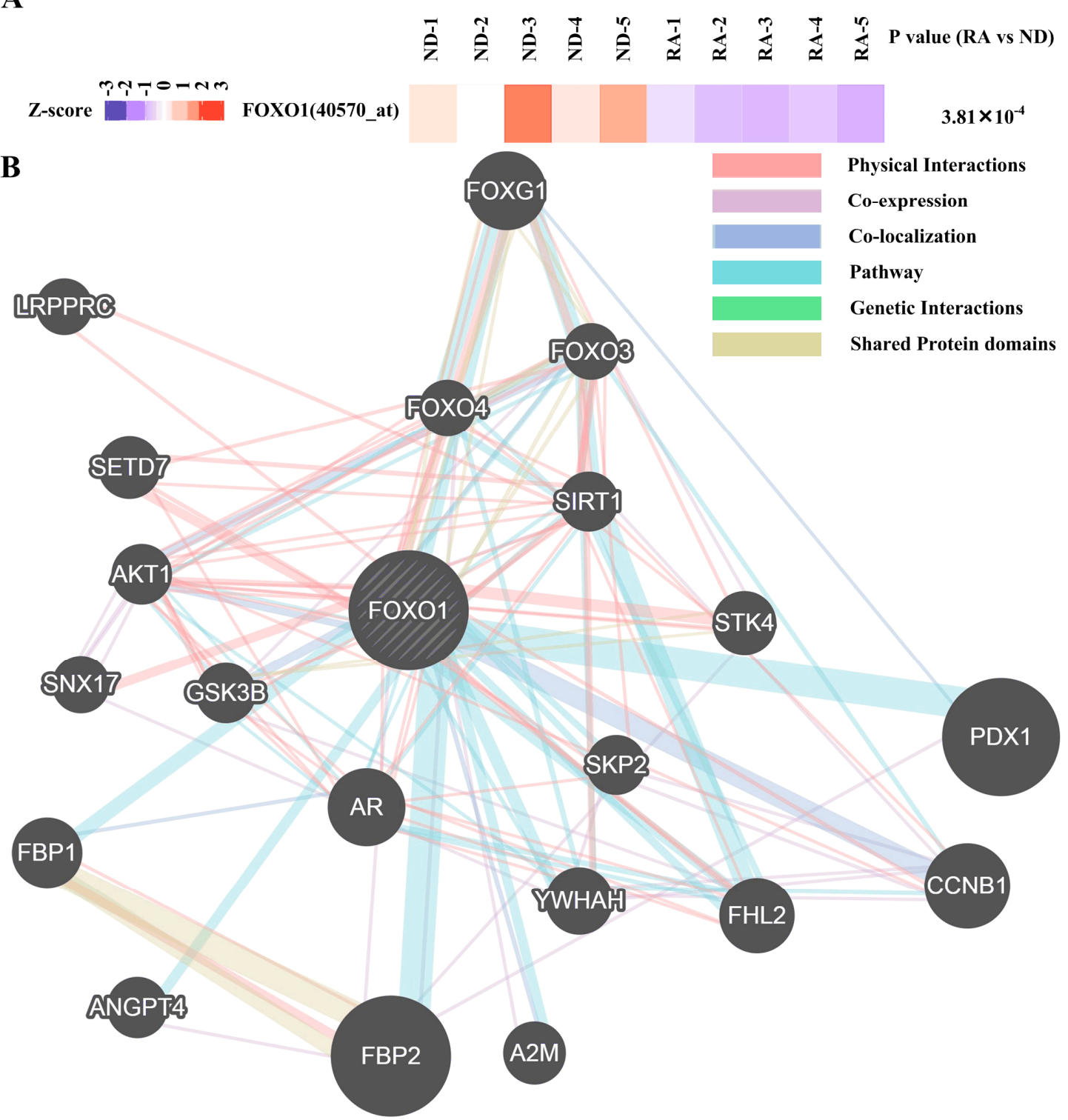

Figure 4. Expression and gene interactions of FOXO. (A) Heatmap showing the scaled expression of FOXO1 in rheumatoid arthritis (RA) synovial fibroblasts and normal donor (ND) synovial fibroblasts as well as P values in GSE1919 with corresponding probe identification shown in parentheses. (B) Gene interaction of FOXO1 with other proteins visualized by Gene Multiple Association Network Integration Algorithm (GeneMANIA) was shown.

\subsection{Validation of Differentially Expressed miRNA}

To confirm differential expression of miRNA in RA synovial fibroblast, we compared our small RNA-seq results with miRNA profiling of GSE37276 [27] (Figure 1, Figure S1). Although eight miRNAs were identified, the role of only one miRNA (hsa-miR-146a-5p) in RA synovial fibroblast has been well-studied [34]. Thus, we focus on remaining two upregulated miRNA and five downregulated miRNAs (Figure S2B, Figure 5, Figure 6A,B). 
A

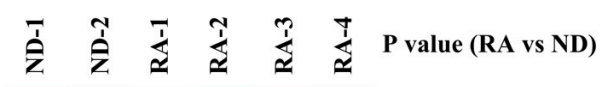

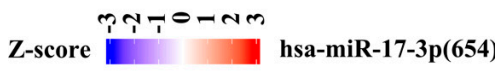

$4.58 \times 10^{-3}$

B

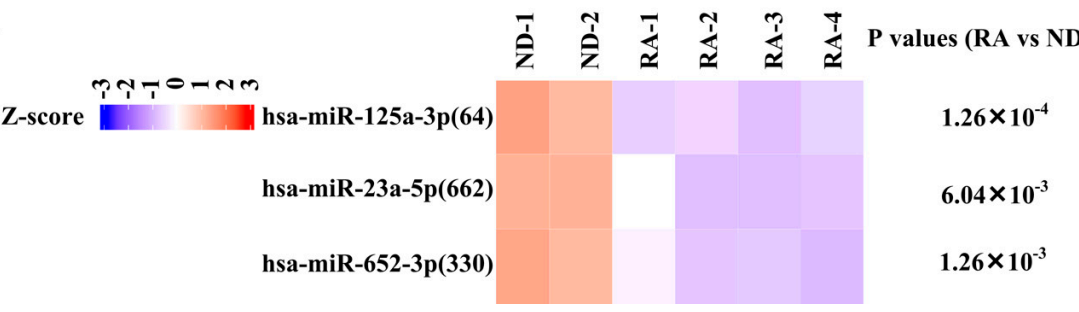

Figure 5. Expression of hsa-miR-17-3p, hsa-miR-125a-3p, hsa-miR-23a-5p, and hsa-miR-652-3p in Gene Expression Omnibus (GEO) dataset. (A) Heatmap showing the scaled expression of upregulated miRNA (hsa-miR-17-3p) in rheumatoid arthritis (RA) synovial fibroblasts compared with normal donor (ND) synovial fibroblasts as well as P value in GSE37276 with probe identification shown in parentheses. (B) Heatmap showing the scaled expression of downregulated miRNA (hsa-miR-125-3p, hsa-miR-23a-5p, hsa-miR-652-3p) as well as P values in GSE37276 with probe identification shown in parentheses.

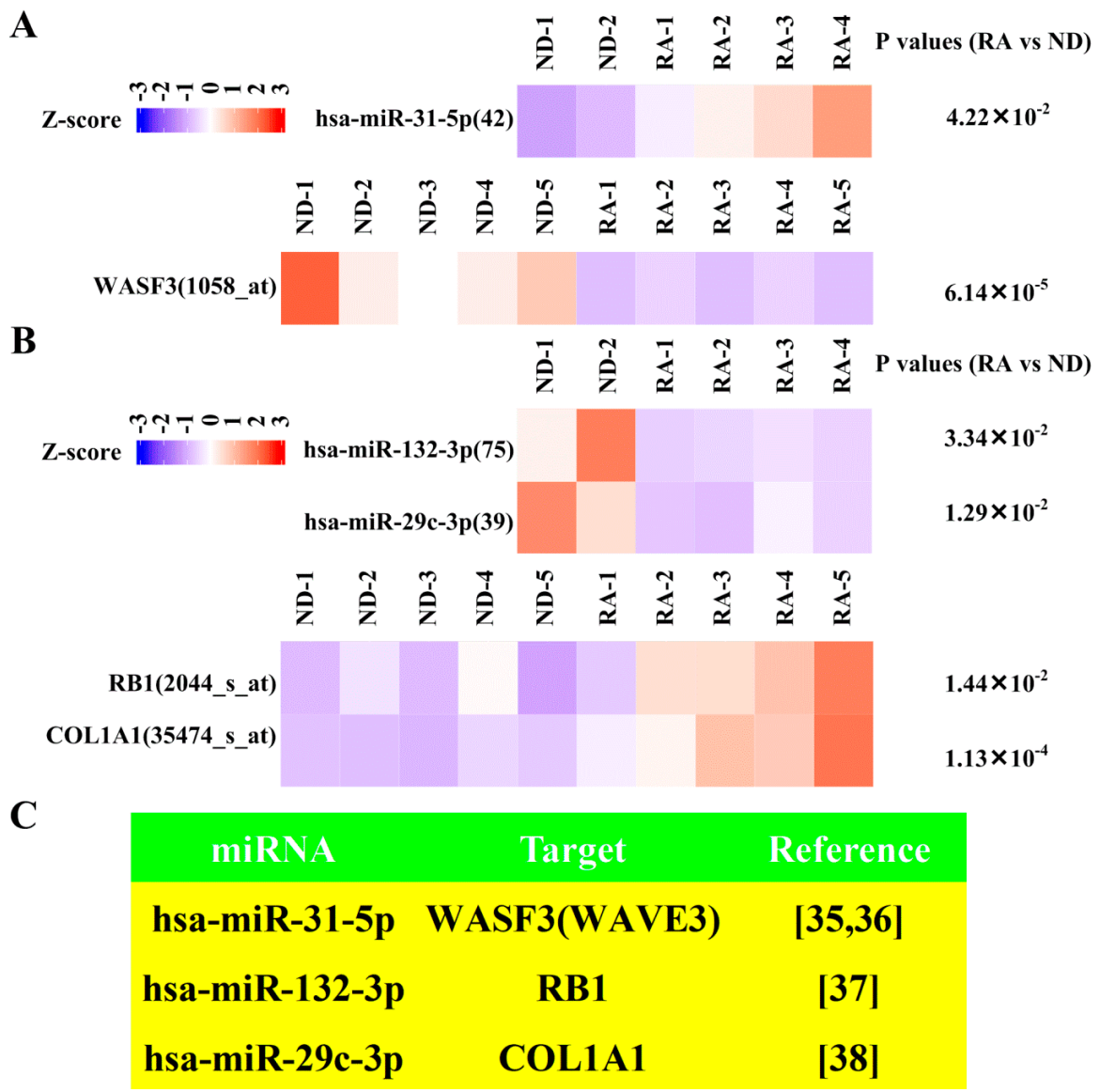

Figure 6. Expression of miRNA (hsa-miR-31-5p, hsa-miR-132-3p, hsa-miR-29c-3p) and corresponding targets (WASF3, RB1, COL1A1) in GEO dataset. (A) Heatmap showing the scaled expression of upregulated miRNA (hsa-miR-31-5p) and downregulated corresponding targets (WASF3) in rheumatoid arthritis (RA) synovial fibroblasts compared with normal donor (ND) synovial fibroblasts as well as $P$ values in GSE1919 and GSE37276 with probe identification shown in parentheses. (B) Heatmap showing the scaled expression of downregulated miRNA (hsa-miR-132-3p, hsa-miR-29c-3p) and upregulated corresponding targets (RB1, COL1A1) in RA and ND synovial fibroblasts as well as P values in GSE1919 and GSE37276 with probe identification shown in parentheses. (C) Literature supporting interactions of miRNA and corresponding targets. 


\subsection{Dysregulated Targets of Validated Upregulated/Downregulated miRNA}

To reveal dysregulated targets of validated upregulated/downregulated miRNA, we first retrieved experimentally verified targets of validated miRNA from miRTarBase (Figure 1). In total, 74 experimentally verified targets of validated upregulated miRNA and 118 experimentally verified targets of validated downregulated miRNA were obtained (Figure S1). After intersection with downregulated mRNA and upregulated mRNA from RNA-seq, 21 upregulated mRNA and 12 downregulated mRNA were revealed (Figure S1). After validation with GSE1919 [25] (Figure 1), one downregulated mRNA (Figure S2A, Figure 6A) and two upregulated mRNA in RNA-seq (Figure S2A, Figure 6B) were singled out. The literature supporting the interaction between these three pairs of miRNA-target genes (hsa-miR-31-5p:WASF3, also called WAVE3, hsa-miR-132-3p:RB1, hsa-miR-29c-3p:COL1A1) [35-38] are shown in Figure 6C.

\section{Discussion}

RA synovial fibroblasts constitute a unique cell type that distinguishes RA from other arthritic conditions and contribute significantly to the initiation and perpetuation of the disease $[39,40]$. Thus a detailed understanding of the internal state of synovial fibroblasts in RA pathogenesis is critical. By combining RNA-seq and small RNA-seq data, this study provides a global view of the transcriptome and miRNA interactome profile and discloses the significant contribution to altered transcriptome by miRNA in RA synovial fibroblasts. Additionally, we identified and validated one transcription factor (FOXO1), which contributed to altered transcriptome in RA synovial fibroblasts utilizing iRegulon and past microarray results [25]. Moreover, three pairs of miRNA-target gene interaction (hsa-miR-31-5p:WASF3, hsa-miR-132-3p:RB1, hsa-miR-29c-3p:COL1A1) were validated through combining small RNA-seq with RNA-seq results, miRTarBase, and previous mRNA/miRNA profiling studies $[25,27]$. These results highlight the particular roles played by these transcription factors and miRNA in RA synovial fibroblasts.

Through interaction analysis of miRNA and target genes, a significant contribution to transcriptome alteration by miRNA was revealed. This exemplifies the complexity of interaction between miRNA and mRNA in RA synovial fibroblasts. This miRNA interactome provides a comprehensive molecular basis for additional information on the pathogenetic mechanisms of rheumatoid arthritis and offer a roadmap to directly probe miRNAs of interest with their likely downstream signaling pathways and functional roles of target proteins. Furthermore, miRNAs target multiple mRNAs in a network and, via dysregulation, implicated in numerous autoimmune diseases [41]. Although targets of several miRNA (hsa-miR-17-3p, hsa-miR-125a-3p, hsa-miR-23a-5p, and hsa-miR-652-3p) (Table S6) failed to be validated with published data, significant evidence of interaction between these targets and corresponding miRNA was found from miRTarBase, and these targets should be followed up in future studies. Moreover, considering the successful application of antisense oligonucleotide strategies in human diseases [42] and therapeutic potential of miRNA in preclinical studies of RA [43], targeting such a dysfunctional miRNA-mRNA interaction may hold promise for RA.

When we annotated differentially expressed transcripts using KEGG database, metabolic pathway was the top-ranking functional category. Several studies demonstrated that the dysregulated synovial cellular bioenergetics switched RA synovial fibroblast profiles and promoted inflammatory natures of RA synovial fibroblasts [44,45]. Furthermore, rewiring of synovial fibroblasts metabolism facilitated resolution of arthritis in the animal model [44,45]. Combined with beneficial effects of metabolic reprogramming in other autoimmune diseases clinically [46], our study draws attention to the therapeutic potential of metabolic reprogramming for RA.

In the step of regulatory network mapping, downregulated FOXO1 was identified as one master regulator. Past studies showed FOXO1 induced apoptosis in RA synovial fibroblasts [47]. Furthermore, differentially expressed genes regulated by FOXO1 (Table S7) also participated in the proliferation, migration, and invasion. For example, CCND1, PAI-1, NOTCH1, ACADM, MEF2C, CDK1, TNNT1, CCNB1, DIO2 facilitated proliferation, migration, and invasion [48-58], while RAB7, RUNX2, ICAM1, 
NFKB1, TXNIP, IL23A, NEP, catalase, GCK, PPARG, PUMA, AXIN2 suppressed proliferation, migration, and invasion [59-71]. These results together suggest a contributing role of FOXO1 in RA synovial fibroblast proliferation (Figure 7).

With regard to miRNA, three pairs of verified miRNA-target interaction with validated differential expression of both miRNA and target genes (hsa-miR-31-5p:WASF3, hsa-miR-132-3p:RB1, hsa-miR-29c-3p:COL1A1) were revealed. Hsa-miR-31-5p inhibited proliferation, migration and invasion of malignant cells [72,73]. Furthermore, WASF3 contributed to cancer cells proliferation, migration and invasion [36]. These findings suggest a regulatory role of hsa-miR-31-5p:WASF3 in ameliorating proliferation, migration, and invasion of RA synovial fibroblast (Figure 7). Concerning hsa-miR-132-3p:RB1, it was well-established that hsa-miR-132-3p increased cell proliferation in pancreatic cells [37], and RB1 inhibited malignant cell proliferation [74]. It is possible that downregulated hsa-miR-132-3p acted as a feedback loop to suppress proliferation of RA synovial fibroblasts (Figure 7). Regarding hsa-miR-29c-3p:COL1A1, it appears hsa-miR-29c-3p inhibited proliferation, migration, and invasion of malignant cells [75]. Moreover, COL1A1 promoted proliferation, migration, and invasion of malignancy [76,77]. As a result, downregulation of hsa-miR-29c-3p and upregulation of COL1A1 potentially enhanced proliferation, migration, and invasion of RA synovial fibroblasts (Figure 7).

Conceptually, some of the present data may seem paradoxical, as some differentially expressed miRNA and mRNA resulted in ameliorated disease. However, it was compatible with current knowledge that upregulated negative feedback loop accompanied disease-promoting processes in disease pathogenesis [78]. Similar phenomena involving miRNA and mRNA have been demonstrated in numerous inflammatory diseases and carcinogenesis. For example, miR-10b-5p, which inhibited production of IL-17, the central cytokine of ankylosing spondylitis, was upregulated in ankylosing spondylitis [79]. IGF-I, which rendered cells susceptible to transformation and thereby contributeed to tumor progression, was decreased in breast cancer [80].

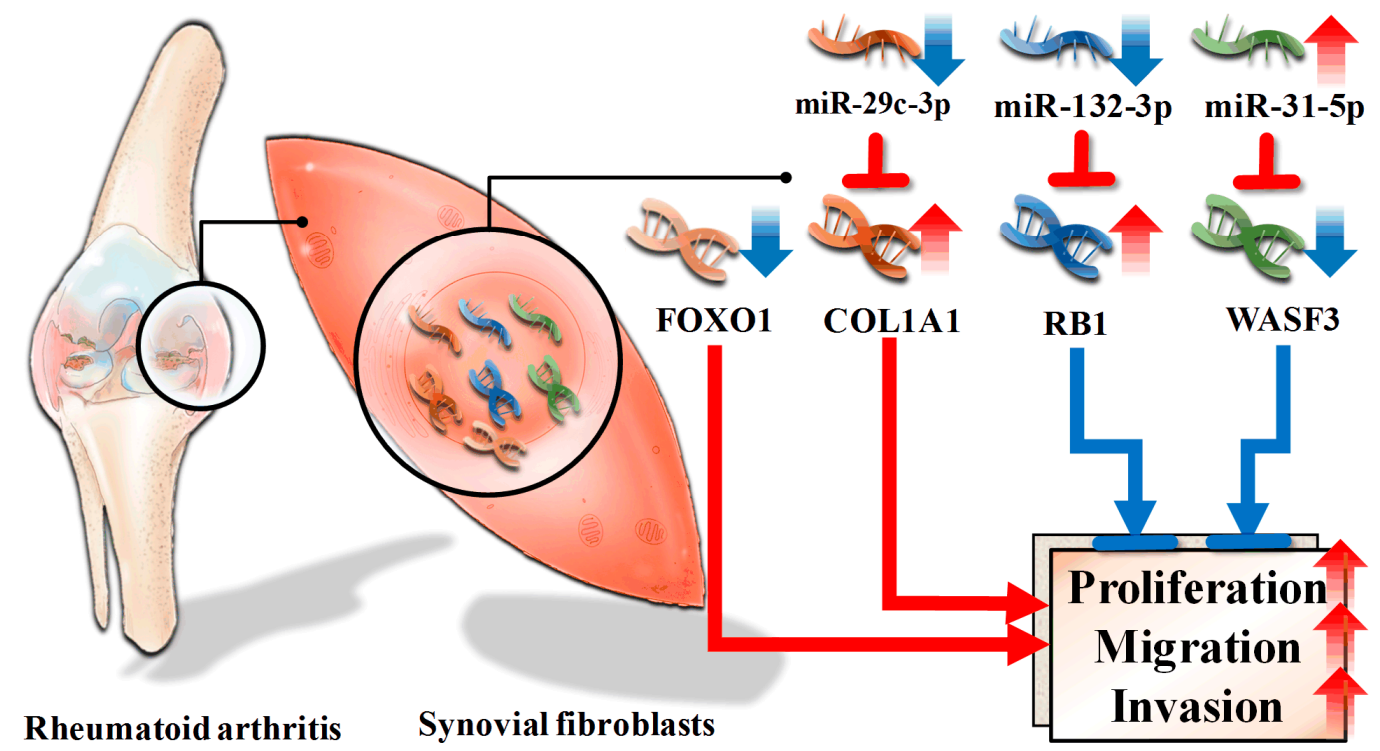

Figure 7. Proposed effects of dysregulated miRNA and transcription factor in rheumatoid arthritis synovial fibroblasts. Downregulated miR-29c-3p resulted in increased COL1A1, together with downregulated FOXO1, increased proliferation, migration, and invasion in rheumatoid arthritis synovial fibroblasts. On the contrary, downregulated miR-132-3p and upregulated miR-31-5p, which contributed to increased RB1 and depressed WASF3, respectively, diminished proliferation, migration, and invasion in rheumatoid arthritis synovial fibroblasts. Inverted T-shape: suppression, blue arrowhead: decrease, red arrowhead: increase, blue arrow: enhancement red arrows: inhibition.

In this study, synovial fibroblasts from normal donor rather than osteoarthritis were used for comparison. Most studies of synovial fibroblasts utilized osteoarthritis synovial fibroblasts as 
controls owing to limited accessibility of normal donor synovial fibroblasts [7,47]. Considering altered transcriptome of osteoarthritis synovial fibroblasts [81], results of this study might be more biologically relevant for RA synovial fibroblasts.

Recent miRNA studies utilized various bioinformatics approaches as screening tools to identify miRNA-mRNA interactome without biological replicates [82,83]. This raised questions about validity of findings from these studies. The identification and validation of miRNA-mRNA target interactions are critical for our understanding of the regulatory networks governing biological processes. In our study, restricting miRNA-mRNA to experimentally validated interactions makes findings of our results more convincing and more suitable to serve as a starting point for investigations of miRNA-based therapies.

\section{Conclusions}

In past decades, advancement in the understanding of molecular bases of disease pathogenesis and the application of new technologies fundamentally transformed our treatment of those diseases [4]. Combining of RNA-seq and small RNA-seq allowed researchers to examine RA synovial fibroblasts at the scale of a complete transcriptome and miRNA interactome. Our analysis identifies transcription factors responsible for an altered transcriptome and elucidates miRNA participating in expression regulation. These findings provide a more comprehensive understanding of the pathophysiology of aberrant synovial fibroblasts activation [39] and the mechanisms underlying the role of synovial fibroblasts in the process leading to RA.

Supplementary Materials: The following are available online at http:/www.mdpi.com/2075-4418/9/3/98/s1.

Author Contributions: C.-C.T., P.-L.K., and J.-H.Y. conceived the project and designed the experiments; L.-Y.W. and P.-L.K. collected samples and performed experiments; C.-C.T., W.-C.T., T.-T.O., C.-C.W., W.-Y.S., and J.-H.Y. analyzed the data; C.-C.T., P.-L.K., and J.-H.Y. wrote the manuscript. All authors read and approved the final manuscript.

Funding: This study was supported by Ministry of Science and Technology (MOST107-2320-B-037-011-MY3), Kaohsiung Medical University Hospital (KMUHS10701; KMUHS10712), Kaohsiung Medical University (KMU-DK108003), and Kaohsiung Municipal Ta-Tung Hospital (KMTTH-107-001).

Acknowledgments: The authors thank the Center for Research Resources and Development of Kaohsiung Medical University.

Conflicts of Interest: The authors declare no conflict of interest.

\section{References}

1. Tonin, F.S.; Steimbach, L.M.; Leonart, L.P.; Ferreira, V.L.; Borba, H.H.; Piazza, T.; Araújo, A.G.; Fernandez-Llimos, F.; Pontarolo, R.; Wiens, A. Discontinuation of non-anti-TNF drugs for rheumatoid arthritis in interventional versus observational studies: A systematic review and meta-analysis. Eur. J. Clin. Pharmacol. 2018, 74, 1513-1521. [CrossRef] [PubMed]

2. Gerlag, D.M.; Safy, M.; Maijer, K.I.; Tang, M.W.; Tas, S.W.; Starmans-Kool, M.J.F.; van Tubergen, A.; Janssen, M.; de Hair, M.; Hansson, M.; et al. Effects of B-cell directed therapy on the preclinical stage of rheumatoid arthritis: The PRAIRI study. Ann. Rheum. Dis. 2019, 78, 179-185. [CrossRef] [PubMed]

3. Kearsley-Fleet, L.; Davies, R.; De Cock, D.; Watson, K.D.; Lunt, M.; Buch, M.H.; Isaacs, J.D.; Hyrich, K.L.; BSRBR-RA Contributors Group. Biologic refractory disease in rheumatoid arthritis: Results from the British Society for Rheumatology Biologics Register for Rheumatoid Arthritis. Ann. Rheum. Dis. 2018, 77, 1405-1412. [CrossRef] [PubMed]

4. Feldmann, M.; Maini, R.N. Perspectives from Masters in Rheumatology and Autoimmunity: Can We Get Closer to a Cure for Rheumatoid Arthritis? Arthritis Rheumatol. 2015, 67, 2283-2291. [CrossRef] [PubMed]

5. Chandrashekara, S.; Shobha, V.; Rao, V.; Desai, A.; Jois, R.; Dharmanand, B.G.; Kumar, S.; Kumar, P.; Dharmapalaiah, C.; Mahendranath, K.M.; et al. Incidence of infection other than tuberculosis in patients with autoimmune rheumatic diseases treated with bDMARDs: A real-time clinical experience from India. Rheumatol. Int. 2019, 39, 497-507. [CrossRef] [PubMed] 
6. Chang, S.K.; Gu, Z.; Brenner, M.B. Fibroblast-like synoviocytes in inflammatory arthritis pathology: The emerging role of cadherin-11. Immunol. Rev. 2010, 233, 256-266. [CrossRef] [PubMed]

7. Stanford, S.M.; Aleman Muench, G.R.; Bartok, B.; Sacchetti, C.; Kiosses, W.B.; Sharma, J.; Maestre, M.F.; Bottini, M.; Mustelin, T.; Boyle, D.L.; et al. TGF $\beta$ responsive tyrosine phosphatase promotes rheumatoid synovial fibroblast invasiveness. Ann. Rheum. Dis. 2016, 75, 295-302. [CrossRef] [PubMed]

8. Müller-Ladner, U.; Ospelt, C.; Gay, S.; Distler, O.; Pap, T. Cells of the synovium in rheumatoid arthritis. Synovial fibroblasts. Arthritis Res. Ther. 2007, 9, 223. [CrossRef]

9. Caiello, I.; Minnone, G.; Holzinger, D.; Vogl, T.; Prencipe, G.; Manzo, A.; De Benedetti, F.; Strippoli, R. IL-6 amplifies TLR mediated cytokine and chemokine production: Implications for the pathogenesis of rheumatic inflammatory diseases. PLoS ONE 2014, 9, e107886. [CrossRef]

10. Borisova, M.A.; Lukina, G.V.; Sigidin, Y.A.; Aronova, E.S.; Luchihina, E.L.; Karateev, D.E.; Glukhova, S.V.; Nasonov, E.L. Efficacy and tolerability of abatacept treatment: Results of 12 months observation. Ter. Arkhiv 2018, 90, 44-49. [CrossRef]

11. Lai, N.S.; Yu, H.C.; Tung, C.H.; Huang, K.Y.; Huang, H.B.; Lu, M.C. Aberrant expression of interleukin-23-regulated miRNAs in T cells from patients with ankylosing spondylitis. Arthritis Res. Ther. 2018, 20, 259. [CrossRef] [PubMed]

12. O’Rourke, M.; Trenkmann, M.; Connolly, M.; Fearon, U.; Murphy, C.C. Novel gene targets for miRNA146a and miRNA155 in anterior uveitis. Br. J. Ophthalmol. 2019, 103, 279-285. [CrossRef] [PubMed]

13. Sato, H.; Muraoka, S.; Kusunoki, N.; Masuoka, S.; Yamada, S.; Ogasawara, H.; Imai, T.; Akasaka, Y.; Tochigi, N.; Takahashi, H.; et al. Resistin upregulates chemokine production by fibroblast-like synoviocytes from patients with rheumatoid arthritis. Arthritis Res. Ther. 2017, 19, 263. [CrossRef] [PubMed]

14. Loh, C.; Park, S.H.; Lee, A.; Yuan, R.; Ivashkiv, L.B.; Kalliolias, G.D. TNF-induced inflammatory genes escape repression in fibroblast-like synoviocytes: Transcriptomic and epigenomic analysis. Ann. Rheum. Dis. 2019. [CrossRef] [PubMed]

15. Sirén, J.; Välimäki, N.; Mäkinen, V. Indexing Graphs for Path Queries with Applications in Genome Research. IEEE/ACM Trans. Comput. Biol. Bioinform. 2014, 11, 375-388. [CrossRef] [PubMed]

16. Trapnell, C.; Williams, B.A.; Pertea, G.; Mortazavi, A.; Kwan, G.; van Baren, M.J.; Salzberg, S.L.; Wold, B.J.; Pachter, L. Transcript assembly and quantification by RNA-Seq reveals unannotated transcripts and isoform switching during cell differentiation. Nat. Biotechnol. 2010, 28, 511-515. [CrossRef] [PubMed]

17. Hsu, Y.L.; Hung, J.Y.; Lee, Y.L.; Chen, F.W.; Chang, K.F.; Chang, W.A.; Tsai, Y.M.; Chong, I.W.; Kuo, P.L. Identification of novel gene expression signature in lung adenocarcinoma by using next-generation sequencing data and bioinformatics analysis. Oncotarget 2017, 8, 104831-104854. [CrossRef]

18. Ramsköld, D.; Wang, E.T.; Burge, C.B.; Sandberg, R. An abundance of ubiquitously expressed genes revealed by tissue transcriptome sequence data. PLoS Comput. Biol. 2009, 5, e1000598. [CrossRef]

19. Jin, W.; Reddy, M.A.; Chen, Z.; Putta, S.; Lanting, L.; Kato, M.; Park, J.T.; Chandra, M.; Wang, C.; Tangirala, R.K.; et al. Small RNA sequencing reveals microRNAs that modulate angiotensin II effects in vascular smooth muscle cells. J. Biol. Chem. 2012, 287, 15672-15683. [CrossRef]

20. Baras, A.S.; Mitchell, C.J.; Myers, J.R.; Gupta, S.; Weng, L.C.; Ashton, J.M.; Cornish, T.C.; Pandey, A.; Halushka, M.K. miRge-A Multiplexed Method of Processing Small RNA-Seq Data to Determine MicroRNA Entropy. PLoS ONE 2015, 10, e0143066. [CrossRef]

21. Hamed, M.; Spaniol, C.; Nazarieh, M.; Helms, V. TFmiR: A web server for constructing and analyzing disease-specific transcription factor and miRNA co-regulatory networks. Nucleic Acids Res. 2015, 43, W283-W288. [CrossRef] [PubMed]

22. Kanehisa, M.; Furumichi, M.; Tanabe, M.; Sato, Y.; Morishima, K. KEGG: New perspectives on genomes, pathways, diseases and drugs. Nucleic Acids Res. 2017, 45, D353-D361. [CrossRef] [PubMed]

23. Mi, H.; Huang, X.; Muruganujan, A.; Tang, H.; Mills, C.; Kang, D.; Thomas, P.D. PANTHER version 11: Expanded annotation data from Gene Ontology and Reactome pathways, and data analysis tool enhancements. Nucleic Acids Res. 2017, 45, D183-D189. [CrossRef] [PubMed]

24. Skinkyte-Juskiene, R.; Kogelman, L.J.A.; Kadarmideen, H.N. Transcription Factor Co-expression Networks of Adipose RNA-Seq Data Reveal Regulatory Mechanisms of Obesity. Curr. Genom. 2018, 19, 289-299. [CrossRef] [PubMed] 
25. Ungethuem, U.; Haeupl, T.; Witt, H.; Koczan, D.; Krenn, V.; Huber, H.; von Helversen, T.M.; Drungowski, M.; Seyfert, C.; Zacher, J.; et al. Molecular signatures and new candidates to target the pathogenesis of rheumatoid arthritis. Physiol. Genom. 2010, 42A, 267-282. [CrossRef] [PubMed]

26. Franz, M.; Rodriguez, H.; Lopes, C.; Zuberi, K.; Montojo, J.; Bader, G.D.; Morris, Q. GeneMANIA update 2018. Nucleic Acids Res. 2018, 46, W60-W64. [CrossRef]

27. Zhu, S.; Pan, W.; Song, X.; Liu, Y.; Shao, X.; Tang, Y.; Liang, D.; He, D.; Wang, H.; Liu, W.; et al. The microRNA miR-23b suppresses IL-17-associated autoimmune inflammation by targeting TAB2, TAB3 and IKK- $\alpha$. Nat. Med. 2012, 18, 1077-1086. [CrossRef]

28. Chou, C.H.; Shrestha, S.; Yang, C.D.; Chang, N.W.; Lin, Y.L.; Liao, K.W.; Huang, W.C.; Sun, T.H.; Tu, S.J.; Lee, W.H.; et al. miRTarBase update 2018: A resource for experimentally validated microRNA-target interactions. Nucleic Acids Res. 2018, 46, D296-D302. [CrossRef]

29. Barrett, T.; Wilhite, S.E.; Ledoux, P.; Evangelista, C.; Kim, I.F.; Tomashevsky, M.; Marshall, K.A.; Phillippy, K.H.; Sherman, P.M.; Holko, M.; et al. NCBI GEO: Archive for functional genomics data sets-update. Nucleic Acids Res. 2013, 41, D991-D995. [CrossRef]

30. Phan, L.M.; Yeung, S.C.; Lee, M.H. Cancer metabolic reprogramming: Importance, main features, and potentials for precise targeted anti-cancer therapies. Cancer Biol. Med. 2014, 11, 1-19.

31. Davis, L.S. A question of transformation: The synovial fibroblast in rheumatoid arthritis. Am. J. Pathol. 2003, 162, 1399-1402. [CrossRef]

32. Li, X.F.; Sun, Y.Y.; Bao, J.; Chen, X.; Li, Y.H.; Yang, Y.; Zhang, L.; Huang, C.; Wu, B.M.; Meng, X.M.; et al. Functional role of PPAR- $\gamma$ on the proliferation and migration of fibroblast-like synoviocytes in rheumatoid arthritis. Sci. Rep. 2017, 7, 12671. [CrossRef]

33. Seemayer, C.A.; Kuchen, S.; Neidhart, M.; Kuenzler, P.; Rihosková, V.; Neumann, E.; Pruschy, M.; Aicher, W.K.; Müller-Ladner, U.; Gay, R.E.; et al. p53 in rheumatoid arthritis synovial fibroblasts at sites of invasion. Ann. Rheum. Dis. 2003, 62, 1139-1144. [CrossRef]

34. Gang, X.; Xu, H.; Si, L.; Zhu, X.; Yu, T.; Jiang, Z.; Wang, Y. Treatment effect of CDKN1A on rheumatoid arthritis by mediating proliferation and invasion of fibroblast-like synoviocytes cells. Clin. Exp. Immunol. 2018, 194, 220-230. [CrossRef]

35. Sossey-Alaoui, K.; Downs-Kelly, E.; Das, M.; Izem, L.; Tubbs, R.; Plow, E.F. WAVE3, an actin remodeling protein, is regulated by the metastasis suppressor microRNA, miR-31, during the invasion-metastasis cascade. Int. J. Cancer 2011, 129, 1331-1343. [CrossRef]

36. Teng, Y.; Ren, M.Q.; Cheney, R.; Sharma, S.; Cowell, J.K. Inactivation of the WASF3 gene in prostate cancer cells leads to suppression of tumorigenicity and metastases. Br. J. Cancer 2010, 103, 1066-1075. [CrossRef]

37. Park, J.K.; Henry, J.C.; Jiang, J.; Esau, C.; Gusev, Y.; Lerner, M.R.; Postier, R.G.; Brackett, D.J.; Schmittgen, T.D. miR-132 and miR-212 are increased in pancreatic cancer and target the retinoblastoma tumor suppressor. Biochem. Biophys. Res. Commun. 2011, 406, 518-523. [CrossRef]

38. Sengupta, S.; den Boon, J.A.; Chen, I.H.; Newton, M.A.; Stanhope, S.A.; Cheng, Y.J.; Chen, C.J.; Hildesheim, A.; Sugden, B.; Ahlquist, P. MicroRNA 29c is down-regulated in nasopharyngeal carcinomas, up-regulating mRNAs encoding extracellular matrix proteins. Proc. Natl. Acad. Sci. USA 2008, 105, 5874-5878. [CrossRef]

39. Huber, L.C.; Distler, O.; Tarner, I.; Gay, R.E.; Gay, S.; Pap, T. Synovial fibroblasts: Key players in rheumatoid arthritis. Rheumatology 2006, 45, 669-675. [CrossRef]

40. Pap, T.; Müller-Ladner, U.; Gay, R.E.; Gay, S. Fibroblast biology. Role of synovial fibroblasts in the pathogenesis of rheumatoid arthritis. Arthritis Res. 2000, 2, 361-367. [CrossRef]

41. Di Marco, M.; Ramassone, A.; Pagotto, S.; Anastasiadou, E.; Veronese, A.; Visone, R. MicroRNAs in Autoimmunity and Hematological Malignancies. Int. J. Mol. Sci. 2018, 19, 3139. [CrossRef]

42. Kristen, A.V.; Ajroud-Driss, S.; Conceição, I.; Gorevic, P.; Kyriakides, T.; Obici, L. Patisiran, an RNAi therapeutic for the treatment of hereditary transthyretin-mediated amyloidosis. Neurodegener. Dis. Manag. 2019, 9, 5-23. [CrossRef]

43. Wu, J.; Fan, W.; Ma, L.; Geng, X. miR-708-5p promotes fibroblast-like synoviocytes' cell apoptosis and ameliorates rheumatoid arthritis by the inhibition of Wnt3a/ $\beta$-catenin pathway. Drug. Des. Devel. Ther. 2018, 12, 3439-3447. [CrossRef]

44. Shi, M.; Wang, J.; Xiao, Y.; Wang, C.; Qiu, Q.; Lao, M.; Yu, Y.; Li, Z.; Zhang, H.; Ye, Y.; et al. Glycogen Metabolism and Rheumatoid Arthritis: The Role of Glycogen Synthase 1 in Regulation of Synovial Inflammation via Blocking AMP-Activated Protein Kinase Activation. Front. Immunol. 2018, 9, 1714. [CrossRef] 
45. Bustamante, M.F.; Oliveira, P.G.; Garcia-Carbonell, R.; Croft, A.P.; Smith, J.M.; Serrano, R.L.; Sanchez-Lopez, E.; Liu, X.; Kisseleva, T.; Hay, N.; et al. Hexokinase 2 as a novel selective metabolic target for rheumatoid arthritis. Ann. Rheum. Dis. 2018, 77, 1636-1643. [CrossRef]

46. Wang, H.; Li, T.; Chen, S.; Gu, Y.; Ye, S. Neutrophil Extracellular Trap Mitochondrial DNA and Its Autoantibody in Systemic Lupus Erythematosus and a Proof-of-Concept Trial of Metformin. Arthritis Rheumatol. 2015, 67, 3190-3200. [CrossRef]

47. Grabiec, A.M.; Angiolilli, C.; Hartkamp, L.M.; van Baarsen, L.G.; Tak, P.P.; Reedquist, K.A. JNK-dependent downregulation of FoxO1 is required to promote the survival of fibroblast-like synoviocytes in rheumatoid arthritis. Ann. Rheum. Dis. 2015, 74, 1763-1771. [CrossRef]

48. Wang, M.; Yu, W.; Gao, J.; Ma, W.; Frentsch, M.; Thiel, A.; Liu, M.; Rahman, N.; Qin, Z.; Li, X. MicroRNA-487a-3p functions as a new tumor suppressor in prostate cancer by targeting CCND1. J. Cell. Physiol. 2019. [CrossRef]

49. Fang, H.; Jin, J.; Huang, D.; Yang, F.; Guan, X. PAI-1 induces Src inhibitor resistance via CCL5 in HER2-positive breast cancer cells. Cancer Sci. 2018, 109, 1949-1957. [CrossRef]

50. Humphries, B.A.; Buschhaus, J.M.; Chen, Y.C.; Haley, H.R.; Qyli, T.; Chiang, B.; Shen, N.; Rajendran, S.; Cutter, A.; Cheng, Y.H.; et al. Plasminogen Activator Inhibitor 1 (PAI1) Promotes Actin Cytoskeleton Reorganization and Glycolytic Metabolism in Triple-Negative Breast Cancer. Mol. Cancer Res. 2019, 17, 1142-1154. [CrossRef]

51. Guo, H.; Wang, F.; Diao, Y.; Zhang, Z.; Chen, Q.; Qian, C.N.; Keller, E.T.; Zhang, J.; Lu, Y. Knockdown of Notch1 inhibits nasopharyngeal carcinoma cell growth and metastasis via downregulation of CCL2, CXCL16, and uPA. Mol. Carcinog. 2019. [CrossRef]

52. Yu, Y.; Zhao, L.; Li, R. Medium-chain acyl-CoA dehydrogenase enhances invasion and metastasis ability of breast cancer cells. Nan Fang Yi Ke Da Xue Xue Bao 2019, 39, 650-656.

53. Xue, W.; Chen, J.; Liu, X.; Gong, W.; Zheng, J.; Guo, X.; Liu, Y.; Liu, L.; Ma, J.; Wang, P.; et al. PVT1 regulates the malignant behaviors of human glioma cells by targeting miR-190a-5p and miR-488-3p. Biochim. Biophys. Acta Mol. Basis Dis. 2018, 1864, 1783-1794. [CrossRef]

54. Tian, Z.; Cao, S.; Li, C.; Xu, M.; Wei, H.; Yang, H.; Sun, Q.; Ren, Q.; Zhang, L. LncRNA PVT1 regulates growth, migration, and invasion of bladder cancer by miR-31/ CDK1. J. Cell Physiol. 2019, 234, 4799-4811. [CrossRef]

55. Shi, Y.; Zhao, Y.; Zhang, Y.; AiErken, N.; Shao, N.; Ye, R.; Lin, Y.; Wang, S. TNNT1 facilitates proliferation of breast cancer cells by promoting G1/S phase transition. Life Sci. 2018, 208, 161-166. [CrossRef]

56. Kuroda, T.; Yasuda, S.; Nakashima, H.; Takada, N.; Matsuyama, S.; Kusakawa, S.; Umezawa, A.; Matsuyama, A.; Kawamata, S.; Sato, Y. Identification of a Gene Encoding Slow Skeletal Muscle Troponin T as a Novel Marker for Immortalization of Retinal Pigment Epithelial Cells. Sci. Rep. 2017, 7, 8163. [CrossRef]

57. Gu, J.; Liu, X.; Li, J.; He, Y. MicroRNA-144 inhibits cell proliferation, migration and invasion in human hepatocellular carcinoma by targeting CCNB1. Cancer Cell Int. 2019, 19, 15. [CrossRef]

58. Kojima, Y.; Kondo, Y.; Fujishita, T.; Mishiro-Sato, E.; Kajino-Sakamoto, R.; Taketo, M.M.; Aoki, M. Stromal iodothyronine deiodinase 2 (DIO2) promotes the growth of intestinal tumors in Apc $\Delta 716$ mutant mice. Cancer Sci. 2019, 110, 2520-2528.

59. Steffan, J.J.; Dykes, S.S.; Coleman, D.T.; Adams, L.K.; Rogers, D.; Carroll, J.L.; Williams, B.J.; Cardelli, J.A. Supporting a role for the GTPase Rab7 in prostate cancer progression. PLoS ONE 2014, 9, e87882. [CrossRef]

60. Teplyuk, N.M.; Galindo, M.; Teplyuk, V.; Pratap, J.; Young, D.W.; Lapointe, D.; Javed, A.; Stein, J.L.; Lian, J.B.; Stein, G.S.; et al. Runx2 regulates $G$ protein-coupled signaling pathways to control growth of osteoblast progenitors. J. Biol. Chem. 2008, 283, 27585-27597. [CrossRef]

61. Ramer, R.; Bublitz, K.; Freimuth, N.; Merkord, J.; Rohde, H.; Haustein, M.; Borchert, P.; Schmuhl, E.; Linnebacher, M.; Hinz, B. Cannabidiol inhibits lung cancer cell invasion and metastasis via intercellular adhesion molecule-1. FASEB J. 2012, 26, 1535-1548. [CrossRef]

62. Yang, D.; Zhang, W.; Liang, J.; Ma, K.; Chen, P.; Lu, D.; Hao, W. Single cell whole genome sequencing reveals that NFKB1 mutation affects radiotherapy sensitivity in cervical cancer. Oncotarget 2017, 9, 7332-7340. [CrossRef]

63. Zhu, G.; Zhou, L.; Liu, H.; Shan, Y.; Zhang, X. MicroRNA-224 Promotes Pancreatic Cancer Cell Proliferation and Migration by Targeting the TXNIP-Mediated HIF1 $\alpha$ Pathway. Cell Physiol. Biochem. 2018, 48, 1735-1746. [CrossRef] 
64. Jiao, D.; Huan, Y.; Zheng, J.; Wei, M.; Zheng, G.; Han, D.; Wu, J.; Xi, W.; Wei, F.; Yang, A.G.; et al. UHRF1 promotes renal cell carcinoma progression through epigenetic regulation of TXNIP. Oncogene 2019, 38, 5686-5699. [CrossRef]

65. Wang, P.; Zhang, Y.; Zhang, J.; Jiang, J.; Jin, F.; Sun, Z. IL-23 concentration-dependently regulates T24 cell proliferation, migration and invasion and is associated with prognosis in patients with bladder cancer. Oncol. Rep. 2018, 40, 3685-3693. [CrossRef]

66. Sumitomo, M.; Shen, R.; Nanus, D.M. Involvement of neutral endopeptidase in neoplastic progression. Biochim. Biophys. Acta. 2005, 1751, 52-59. [CrossRef]

67. Li, W.; Jiang, Z.; Xiao, X.; Wang, Z.; Wu, Z.; Ma, Q.; Cao, L. Curcumin inhibits superoxide dismutase-induced epithelial-to-mesenchymal transition via the PI3K/Akt/NF- KB pathway in pancreatic cancer cells. Int. J. Oncol. 2018, 52, 1593-1602. [CrossRef]

68. Tornovsky-Babeay, S.; Dadon, D.; Ziv, O.; Tzipilevich, E.; Kadosh, T.; Schyr-Ben Haroush, R.; Hija, A.; Stolovich-Rain, M.; Furth-Lavi, J.; Granot, Z.; et al. Type 2 diabetes and congenital hyperinsulinism cause DNA double-strand breaks and p53 activity in $\beta$ cells. Cell Metab. 2014, 19, 109-121. [CrossRef]

69. Wu, Y.; Song, T.; Liu, M.; He, Q.; Chen, L.; Liu, Y.; Ni, D.; Liu, J.; Hu, Y.; Gu, Y.; et al. PPARG Negatively Modulates Six2 in Tumor Formation of Clear Cell Renal Cell Carcinoma. DNA Cell Biol. 2019, 38, 700-707. [CrossRef]

70. Tu, S.; Zhang, X.L.; Wan, H.F.; Xia, Y.Q.; Liu, Z.Q.; Yang, X.H.; Wan, F.S. Effect of taurine on cell proliferation and apoptosis human lung cancer A549 cells. Oncol. Lett. 2018, 15, 5473-5480. [CrossRef]

71. Xie, H.; Huang, H.; Huang, W.; Xie, Z.; Yang, Y.; Wang, F. LncRNA miR143HG suppresses bladder cancer development through inactivating Wnt/ $\beta$-catenin pathway by modulating miR-1275/AXIN2 axis. J. Cell. Physiol. 2019, 234, 11156-11164. [CrossRef]

72. Bi, J.; Liu, H.; Cai, Z.; Dong, W.; Jiang, N.; Yang, M.; Huang, J.; Lin, T. Circ-BPTF promotes bladder cancer progression and recurrence through the miR-31-5p/RAB27A axis. Aging 2018, 10, 1964-1976. [CrossRef]

73. Hashemi, Z.S.; Moghadam, M.F.; Farokhimanesh, S.; Rajabibazl, M.; Sadroddiny, E. Inhibition of breast cancer metastasis by co-transfection of miR-31/193b-mimics. Iran. J. Basic Med. Sci. 2018, 21, 427-433.

74. Henry, T.J.; Chng, W.J.; Carpten, J.; Bergsagel, P.L.; Fonseca, R. RB1 Haploinsufficiency Confers a Proliferation Advantage in Myeloma Cell Lines. Blood 2007, 110, 2489.

75. Nishikawa, R.; Chiyomaru, T.; Enokida, H.; Inoguchi, S.; Ishihara, T.; Matsushita, R.; Goto, Y.; Fukumoto, I.; Nakagawa, M.; Seki, N. Tumour-suppressive microRNA-29s directly regulate LOXL2 expression and inhibit cancer cell migration and invasion in renal cell carcinoma. FEBS Lett. 2015, 589, 2136-2145. [CrossRef]

76. Zhang, Z.; Fang, C.; Wang, Y.; Zhang, J.; Yu, J.; Zhang, Y.; Wang, X.; Zhong, J. COL1A1: A potential therapeutic target for colorectal cancer expressing wild-type or mutant KRAS. Int. J. Oncol. 2018, 53, 1869-1880. [CrossRef]

77. Liu, J.; Shen, J.X.; Wu, H.T.; Li, X.L.; Wen, X.F.; Du, C.W.; Zhang, G.J. Collagen 1A1 (COL1A1) promotes metastasis of breast cancer and is a potential therapeutic target. Discov. Med. 2018, 25, 211-223.

78. Mnjoyan, Z.H.; Dutta, R.; Zhang, D.; Teng, B.B.; Fujise, K. Paradoxical upregulation of tumor suppressor protein p53 in serum-stimulated vascular smooth muscle cells: A novel negative-feedback regulatory mechanism. Circulation 2003, 108, 464-471. [CrossRef]

79. Chen, L.; Al-Mossawi, M.H.; Ridley, A.; Sekine, T.; Hammitzsch, A.; de Wit, J.; Simone, D.; Shi, H.; Penkava, F.; Kurowska-Stolarska, M.; et al. miR-10b-5p is a novel Th17 regulator present in Th17 cells from ankylosing spondylitis. Ann. Rheum. Dis. 2017, 76, 620-625. [CrossRef]

80. Haffner, M.C.; Petridou, B.; Peyrat, J.P.; Révillion, F.; Müller-Holzner, E.; Daxenbichler, G.; Marth, C.; Doppler, W. Favorable prognostic value of SOCS2 and IGF-I in breast cancer. BMC Cancer 2007, 7, 136. [CrossRef]

81. Del Rey, M.J.; Usategui, A.; Izquierdo, E.; Cañete, J.D.; Blanco, F.J.; Criado, G.; Pablos, J.L. Transcriptome analysis reveals specific changes in osteoarthritis synovial fibroblasts. Ann. Rheum. Dis. 2012, 71, 275-280. [CrossRef] 
82. Yin, J.H.; Liu, C.S.; Yu, A.P.; Yao, J.Q.; Shen, Y.J.; Cao, J.P. Pro-Angiogenic Activity of Monocytic-Type Myeloid-Derived Suppressor Cells from Balb/C Mice Infected with Echinococcus Granulosus and the Regulatory Role of miRNAs. Cell. Physiol. Biochem. 2018, 51, 1207-1220. [CrossRef]

83. Ren, H.; Yu, X.; Shen, G.; Zhang, Z.; Shang, Q.; Zhao, W.; Huang, J.; Yu, P.; Zhan, M.; Lu, Y.; et al. miRNA-seq analysis of human vertebrae provides insight into the mechanism underlying GIOP. Bone 2019, 120, 371-386. [CrossRef]

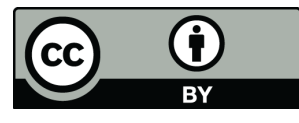

(C) 2019 by the authors. Licensee MDPI, Basel, Switzerland. This article is an open access article distributed under the terms and conditions of the Creative Commons Attribution (CC BY) license (http://creativecommons.org/licenses/by/4.0/). 